\title{
O inavaliável em uma sociedade de desconfiança*
}

Claudine Haroche*

\section{Resumo}

Vivemos presentemente em sociedades de controle contínuo que induzem e reforçam a falta de confiança e, além disso, uma desconfiança difusa e crescente que nos leva a falar de sociedade de desconfiança. Nestas sociedades exige-se tanto dos organismos como dos indivíduos que prestem conta, com precisão, não tanto daquilo que fizeram, mas do que fazem no momento presente, assim como o que pretendem fazer: procura-se assim suprimir a perda de tempo, a falta de rentabilidade e, mais ainda, o imprevisível, inavaliável por definição. Em face do ininteligivel provocado e intensificado pela mudança permanente, ligada entre outras coisas à aceleração das tecnologias, a sociedade foi levada a desenvolver ferramentas de avaliação; indiferente ao indivíduo em sua singularidade, a avaliação tende a individualizá-lo e controlá-lo incessantemente e, ao mesmo tempo, a diferenciá-lo e homogeneizá-lo cada vez mais. Atualmente, os bens e as pessoas são cada vez mais avaliados e, portanto, inevitavelmente comparados, engendrando e reforçando formas de concorrência e rivalidade permanentes e exacerbadas.

\section{Palavras-chave}

Inavaliável - Processo de pensamento - Controle contínuo Sociedade de desconfiança - Avaliação.
* Primeira publicação em Cadernos Internacionais de Sociologia, v. CXXVIII-CXXIX (53-78), 2010.

** A tradução do francês foi feita por Marcia Vinci de Moraes e a revisão técnica da tradução foi feita por Olgária Matos. 


\section{L'inevaluable dans une societe de défiance*}

Claudine Haroche

\section{Résumé}

Nous sommes ci présent dans des sociétés de contrôle continu qui induisent et renforcent le manque de confiance, et au-delà une défiance diffuse et grandissante qui conduit à parler de société de défiance. Dans ces sociétés, il est exigé, des organismes comme des individus, de rendre compte avec précision non tant de ce qu'ils ont fait, mais de ce qu'ils sont en train de faire dans le moment présent, et tout autant de ce qu'ils envisagent de faire : on cherche ainsi à supprimer la perte de temps, le manque de rentabilité, mais encore l'imprévisible par définition inévaluable. Face à l'inintelligible provoqué et intensifié par le changement permanent lié entre autres à l'accélération des technologies, la société a été amenée à développer des outils d'évaluation ; indifférente à l'individu dans sa singularité, l'évaluation tend dans le même temps à l'individualiser et le contrôler incessamment, à le différencier et l'homogénéiser toujours davantage. Les biens et les personnes sont aujourd'hui de plus en plus évalués, et en cela inévitablement comparés, engendrant et renforçant des formes de concurrence et de rivalité permanentes et exacerbées.

\section{Mots clés:}

Inévaluable - Processus de pensée - Contrôle continu - Société de défiance - Évaluation.

* Initialement publié dans les Cahiers internationaux de Sociologie, v. CXXVIII-CXXIX (53-78), 2010 
"Quando confiam em nós, somos quase envolvidos por um julgamento que nos é feito por antecipação (...). A confiança se "dá"; não podemos exigir que ela nos seja dada como exigimos não ficar decepcionados, quando nos é concedida". (Simmel)

As sociedades contemporâneas neoliberais assistiram à emergência de trabalhos consagrados às formas inéditas do vínculo social, aos seus estados-limite e, além disso, e mais fundamentalmente, ao seu questionamento ${ }^{1}$. 0 que faltou ao vínculo social? 0 que negligenciamos, ignoramos ou perdemos em relação a ele para que aconteça tamanha perda de confiança? E para que se instaure de forma contínua, extensa e generalizada um clima, ou uma atmosfera de desconfiança que a sociedade apreende e reforça, através da avaliação cifrada, econômica e monetária de tudo e de todos? A relação com a temporalidade e também com o espaço foram abaladas pela extensão das tecnologias: a aceleração e a velocidade puseram em foco as referências e os quadros espaço-temporais, os limites são atualmente ignorados pela desterritorialização na globalização².

Em face do incompreensível, do ininteligível e do opaco provocados e intensificados pela mudança permanente ligada entre outras coisas à aceleração das tecnologias, a sociedade foi conduzida a desenvolver ferramentas de avaliação; indiferente ao indivíduo em sua singularidade, a avaliação tende, ao mesmo tempo, a individualizá-lo e controlá-lo incessantemente e a diferenciá-lo e homogeneizá-lo cada vez mais ${ }^{3}$.

1. Faço questão de agradecer Myriam Bahia Lopes, Alice Canabate, Mariana Cortes, Yves Déloye, Joel Birman, Eliana Kuster e Eugene Enriquez por suas numerosas notas e sugestões.

2. Ver em particular G. Balandier, Le Grand Dérangement, PUF, 2005: Le Dépaysement contempórain. L'i mmédiat et l'essentiel. Entrevistas com J. Birman \& Cl Haroche, PUF, 2009: P. Virilio, Vitesse et politique, Galilée, 1977; Le Futurisme de l'instant, Galilée, 2009. L'Administration de la peur (Conversation pour demain), Textuel, 2010; Z. Bauman, Society under Siege, Cambridge, Polity Press. 2002. Modern liquidity, Cambridge, Polity Press, 2000; R. Sennett, Le Travail sans qualité. Les conséquences humaines de la flexibilité (1998), Paris, Albin Michel, 2000; La Culture du nouveau capitalisme (2006), Alvi n Michel, 2006; ver igualmente Cl. Haroche, L'Avenir du sensible (Les sens et les sentiments en question), Paris, PUF, 2008, assim como: "L'Absence d'interdit dans l'illimitation contemporaine", em Droits et cultures, v. LVII, 2009/1.

3. Ver as contribuições de Joel Birman e Arie-Anne Dujarier
Estamos doravante muito além daquilo que chamamos sociedades disciplinares e sociedades de controle: estamos atualmente dentro de sociedades de controle contínuo onipresente, que provocam e acentuam a falta de confiança; além de uma suspeita e uma desconfiança difusa e crescente, tanto da parte das instituições - sociais, econômicas, financeiras, educativas, universitárias, políticas e empresariais - como da parte dos indivíduos no mundo do trabalho e no vínculo social e privado de maneira geral ${ }^{4}$. Isto nos leva a falar de sociedade de desconfiança. Esta sociedade reflete e revela um clima psicológico, moral, social e político que encoraja e desenvolve um tipo de personalidade ou caráter evasivo, inapreensível e defensivo.

Nestas sociedades, tanto os organismos quanto os indivíduos devem prestar contas, com precisão, não somente daquilo que fizeram, mas do estão fazendo no momento presente e também do que pensam fazer. Isto supõe cifrar para procurar suprimir tudo o que é considerado perda de tempo, falta de rentabilidade, tudo o que é julgado inútil, imprevisível, portanto inédito e, em outros termos, tudo o que é inavaliável por definição. Constantemente, é preciso prestar contas aos organismos de tutela, à administração e à sociedade. Os bens - com exceção de mecanismos financeiros complexos ou opacos, - os vínculos e as pessoas são, atualmente, cada vez mais avaliados - portanto inevitavelmente comparados - engendrando e reforçando formas de concorrência e rivalidade permanentes e exacerbadas.

\section{Um resíduo inacessível: o sentido}

subjetivo da atividade social

Desde o fim do século XIX, Durkheim e Weber trabalharam na observação de fatos difusos ligados em particular à instabilidade e à incerteza do conjunto da sociedade moderna.

4. Sobre as sociedades de controle, ver G. Deleuze, "Controle et Devenir", assim como "Post-scriptum sur les sociétés de controle" em Pourparlers (1972-1990\0, Paris, Editions de Minuit, (1990/2003, 2007. A disciplina no entanto despareceu nas sociedades de controle: difusa, insidiosa, incontornável, poderia ser mais difícil de combater que no passado. 
Desde então foram confrontados com as questões de qualificação, classificação e percepção do social, da sociedade.

Em 1984, em As regras do método sociológico, Durkheim colocou a questão de saber o que é um fato social, reconhecendo o caráter decisivo, porém inevitavelmente impreciso dos fatos sociais. "Emprega-se comumente (esta qualifıcação) para designar, aproximadamente, todos os fenômenos que acontecem no interior da sociedade." Ele propôs precisar estes fatos, sublinhando que "eles não poderiam confundir-se nem com fatos orgânicos, pois consistem em representações e ações, nem com os fenômenos psíquicos, existentes apenas na e pela consciência individual". Durkheim concluiu, então, que "eles constituem uma espécie nova e é a eles que deve ser dada e reservada a qualificação de sociais"'.

Porém, além do fato social, existe a questão ainda mais vasta e mais abrangente da atividade social à qual se dedicou Weber, desde o primeiro capítulo de Economia e socieda$d e$, quando procurou estabelecer "as categorias da sociologia". "Entendemos por atividade um comportamento humano (pouco importa tratar-se de ato exterior ou intimo...), quando e na medida em que o agente ou agentes lhes comuniquem um sentido subjetivo", dizia Weber. Aprofundando dessa forma a relação entre comportamento reacional, não refletido e atividade significativa, intencional, em vigor nos funcionamentos sociais complexos e paradoxais, Weber prosseguia: "A fronteira entre uma atividade significativa e um comportamento (que chamarei aqui) simplesmente reacional, porque não associado a um sentido visado subjetivamente, é absolutamente flutuante. Uma parte considerável do conjunto dos comportamentos sociologicamente importantes (...) se situa no limite dos dois"6. Enfım, Weber insistia sobre os limites da sociologia interpretativa conten-

5. Durkheim, Les Règles de ma méthode sociologique (1984), Paris, Flammarion, 1988, p. 95 e 97.

6. Weber, Économie et société, t.l, "Les catégories de la sociologie", Paris, Plon, Agora Pocket, 1995, p. 2. do, efetivamente, "para além da constatação de relações e regras ("as leis") funcionais, alguma coisa a mais que permanece eternamente inacessivel a toda ciência da natureza (...). Trata-se da compreensão do comportamento dos indivíduos singulares participantes ${ }^{7}$.

Esta alguma coisa eternamente inacessivel a qualquer ciência da natureza, como colocava Weber, permanece igualmente inacessível a qualquer ciência social e deveria, para respeitar a liberdade e a singularidade de todo indivíduo, permanecer inacessivel a todo poder: é a parte do imprevisível do imprevisto, do inédito, de liberdade fundamental nas relações consigo mesmo, que incita, ou deveria impor o respeito aos indivíduos em sua singularidade.

Em que consistem estes fatos difusos, este resíduo inacessível, este inavaliável? Qual é o seu papel? Têm alguma importância? Aparecem como o fundo, o último plano, quer se trate do longínquo, do horizonte, do indiscernível ou do intangível, ou ainda, sob a forma de detalhes insignificantes que nascem da dificuldade de discernir o banal, o cotidiano ou o invisível na sociedade ${ }^{8}$. Aparecem, ainda, como objetos sem preço, de tal forma são preciosos, raros ou únicos: dificilmente encontrados ou substituíveis, não dependentes verdadeiramente do mercado ${ }^{9}$. Acontecimentos efêmeros, únicos, ligados à beleza ou à perfeição de uma representação, de um concerto, de uma ópera, da execução de um pianista, de um violoncelista, da voz de uma soprano; ou, ainda, ligados à qualidade dos vínculos, das afinidades, dos sentimentos que não poderiam depender do mercado: a mesma coisa que a atmosfera calorosa, o ambiente agradável,

\footnotetext{
7. Ibid., p. 29.

8. Ibid. P. 43. Eles estiveram no centro das preocupações de numerosos trabalhos: os de Mauss sobre os quais Lévi Strauss escrevera um prefácio para Sociologie et Anthropologie (1950), Paris, PUF, 2004: os de C. Ginsburg em "Signes, Traces, Pistes", Ensaio para um paradigma do índice (1979), publicado em Le Débat (1980) depois retomado em Mythes, Emblèmes, Traces. Morphologie et Histoire, Flammarion (1986) 1989, sob 0 título Traces. Racines d'um paradigme indiciaire: ainda os de M. De Certeau L'invention du quotidien, L'art de faire, t.1, Galimmard, 1990.

9. Simmel, Philosophie de l'argent, Paris, PUF, 1987; J. Duvignaud, Le prix des choses sans prix, Actes Sud, 2001.
} 
o clima amigável; a mesma coisa ainda que a afabilidade, a generosidade, a abertura de espírito, o interesse despertado, o interesse por uma troca, uma conversa, as deferências, as atenções, o calor humano. Há evidentemente qualidades, vínculos ou acontecimentos que contêm um valor que não se pode avaliar, medir ou contar: são inapreciáveis, inestimáveis, sem preço.

Mas, é a outro resíduo inacessível que nos dedicamos aqui: o inavaliável presente em todo indivíduo. Em cada pessoa persiste uma parte não avaliável, uma singularidade ligada à história, à vivência pessoal, que constitui uma parte não transparente: em alguns momentos inteligíveis a si mesmo ou ao outro, ela permanece geralmente oculta do olhar exterior. Trata-se do intimo que constitui também e, ao mesmo tempo, uma garantia do foro interior, do desejo secreto de cada um. Simmel, referindo-se ao território do intimo, foi um dos primeiros a perceber seu caráter crucial na modernidade, a colocar que este inavaliável não pode ser acessível e que deve ser protegido ${ }^{10}$.

Outrora ritualizados, codificados e, portanto, de certa maneira separados, os vínculos, os bens e as relações tendem hoje em dia a se confundir ${ }^{11}$. Doravante, o foro interior é o lugar de intrusões múltiplas, constantes e ilimitadas, prendendo-se a uma psicologização e a uma tecnologização da sociedade como um todo, seja no âmbito do trabalho, da empresa, do direito ou dos vínculos sociais. Esta psicologização tende a apagar a fronteira com o exterior, tocando, por este motivo, o espaço interior e a liberdade do indivíduo na relação consigo mesmo. 0 questionamento da propriedade de si mesmo, concomitante

10. Simmel, Soziologie, "le secret et la société secrète" (chap.V), Paris, PUF, 1999; ver Le for intérieur, (sob a direção de Cl.Haroche), PUF - Curapp, 1995, em particular o artigo de D.Enriquez, "Approche du for intérieur".

11. Sobre a codificação e a separação, ver N.Élias, La Civilisation des moeurs (1939), Paris Calmann Lévy, 1973, e La Dynamique de l'Occident (1969), Paris, Calmann Lévy, 1975, assim como La Société des individus ((1987), Fayard, 1991, introdução de R.Chartier, em particular "Conscience de soi et image de l'homme" (1940-1950). com a ignorância da parte de singularidade de cada um, nasce das evoluções de uma sociedade mercenária na qual se generalizou a extensão de contratos múltiplos e diversificados limitados no tempo, de seu caráter mais restritivo em todos os domínios e do declínio da proteção geral que a lei oferecia. Individualizar, contar, medir, cifrar são atos que se tornaram contínuos. Estas evoluções tendem a passar silenciosamente de uma disposição de espírito se desenvolvendo dentro de uma relativa confiança a certa forma de desconfiança.

Podemos preservar esta parte do inavaliável na subjetividade, os modos como o sujeito comunica um sentido subjetivo à atividade social e, então, discernir os modos de subjetivação? Hoje em dia somos confrontados com uma espécie até então despercebida de fatos sociais?

\section{Fatos sociais inéditos}

Desejamos aqui tratar estas questões de um ângulo relativamente pouco abordado até agora, partindo de Weber, no que se refere à parte inacessível no comportamento dos indivíduos e, por consequência, a questão da confiança. Esta parte inavaliável que traduz a existência de uma singularidade em cada indivíduo é ignorada, negada pela sociedade contemporânea. Ela não tem mais lugar numa sociedade de desconfiança.

Simmel tinha tentado revelar a articulação entre bens objetivos e propriedades subjetivas na relação consigo mesmo e elucidar os vínculos entre propriedade de si mesmo, confiança em si e no outro que constituem a base das sociedades na modernidade ${ }^{12}$.

12. Simmel, Philosophie de l'argent, op. cit ; Sociologie. Études sur les formes de socialisation, (1908; 1992), Paris, PUF, 1999. Sobre a questão das relações entre a propriedade de si e a propriedade social, R.Castel, Cl.Haroche, Propriété privée, propriété sociale, propriété de soi. Entretiens sur la construction de l'individu moderne, Paris, Fayard, 2001 (rééd. Hachette Pluriel, 2005) em particular a quarta parte. Desejo continuar e aprofundar aqui a abordagem que orientou meu propósito. Eu tinha colocado a questão de saber como qualificar, apreender os bens como 0 estatuto, a função, o cargo, sublinhando que se tratava ao mesmo tempo de bens 
Ele, que percebeu o fundamento da própria ideia de sociedade, nos permite captar os papéis decisivos da confiança, da fidelidade e das questões que se tornaram cruciais e que vigoram na contemporaneidade. Contribui, assim, para decifrar certos grandes transtornos nas sociedades modernas: o afastamento, a rejeição, a estigmatizacão, a supressão da parte inavaliável pela avaliação, medindo precisamente o seu papel na crise da confiança e na emergência de uma desconfiança ampliada.

A "escalada da insignificância"13, a extensão de uma indiferença progressiva, de uma perda de confiança, até mesmo da hostilidade com relação à singularidade individual, acompanham o afastamento do inavaliável e, de forma mais geral, daquilo que não é comparável - o incomparável - daquilo que não depende de categorias e classificações conhecidas ${ }^{14}$.

A avaliação incessante, transformada em "instrumento" do controle contínuo que ignora, quando não despreza, o indivíduo isolado na sua singularidade, depende dessa desconfiança e a reforça. Ela tenta reduzir a parte de desconhecido, reconduzindo-a doravante à cifra, à quantificação, à linguagem formal da governança, sem conteúdo e substância nas sociedades onde os funcionamentos e as identidades são fragmentados, misturados, múltiplos, instáveis, difusos e incertos. 0 valor doravante cifrado tende a ser desprovido de conteúdo.

Assim nos dedicamos, à luz dos escritos de Simmel, a elucidar, primeiramente, a gênese dos processos subjacentes ao inavaliável: estes são concomitantes com a passagem de uma subordinação técnica que tenderá a se apagar diante de uma subordinação subjetiva.

objetivos e subjetivos: bens objetivos indissociáveis de bens e propriedades subjetivas. Eu sublinhava que se tratava de um nível de interações evidentemente complexo, mas que era interessante - crucial - procurar analisar o que Simmel soube mostrar na Philosophie de l'argent, coisas ao mesmo tempo abstratas e concretas, objetivas e subjetivas, que é importante e até mesmo necessário tentar qualificar com precisão, estando elas doravante vigorando no coração das sociedades contemporâneas.

13. A expressão é de Castoriadis, La montée de l'insignifiance, Paris, Seuil, 1996.

14. Weber, Économie et société. Les catégories de la Sociologie, op. cit.
Esta última induz e reforça um abalo, ou pelo menos um questionamento do universo interior do indivíduo, refletindo e exacerbando o exercício de uma dominação sobre a relação consigo mesmo que toma, entre outras, a forma de uma psicologização ${ }^{15}$, ela é concomitante com a passagem de uma sociedade onde reina uma relativa confiança em outra onde a desconfiança tende a dominar.

Passaremos em seguida a certas abordagens filosóficas, jurídicas, sociológicas e psicanalíticas referentes às sociedades neoliberais contemporâneas, em particular as de Supiot, Waters, Miller, Gauchet e Zarka: estes autores observam o recuo do caráter geral do conhecimento, da cultura e da lei, correspondendo este recuo às exigências de produtividade nas sociedades de mercado que se manifestam nas empresas, referindo-se doravante a todas as esferas da sociedade através da extensão dos saberes competentes ${ }^{16}$. Estes tipos de saberes são acompanhados da ignorância da singularidade de cada um, da eliminação do julgamento e do discernimento individual e em consequência da parte irredutível do inavaliável que preserva uma liberdade no julgamento e no pensamento de cada um: enfim, estes saberes incitam o desenvolvimento de um tipo de personalidade marcado profundamente por traços de dependência, de submissão, de conformidade e de desconfiança.

\section{O imponderável, o não mensurável, o singular}

Simmel estabeleceu e descreveu os processos subjacentes à gênese, às próprias condições das relações entre os bens e as pessoas,

15. A psicologização que pode revestir múltiplos aspectos - familiaridade, ignorância das formas, mediações, informalidade, conivência - ignora e questiona esta parte do inacessivel. Ver em particular o cap. V: "Des formes et des manières em Démocratie”, L'Avenir du sensible, op.cit., p.121.

16. A. Supiot, L'Esprit de Philadelphie, "La justice sociale face au marché total", Paris, Seuil, 2010; J. A. Miller, J. C. Milner, Voulez-vous être évalué? Paris, Grasset, 2005; L. Waters, Enemies of Promise: Publishing, Perishing and the Eclipse os Scholarship, University of Chicago Press, 2004; M. Gauchet, "Vers une société de l'ignorance?", em Le Débat, n.156. setembro/ outubro 2009; Y.-C.Zarka, editorial, "Qu'est-ce que tyranniser le savoir?", assim como "L'évaluation : un pouvoir suposto saber", em Cités, n. 37, Paris, PUF, 2009. 
bens qualitativos, bens sem preço, tais como confiança, fidelidade e dignidade. Ele sublinha que, de certa maneira, a questão da confiança não se colocava, de tal forma ela era evidente; "nas sociedades mais primitivas e menos diferenciadas sabia-se muito mais sobre o seu parceiro do ponto de vista pessoal" e, por isso, "muito menos quanto à possibilidade puramente objetiva de confiar nele" ${ }^{17}$.

De hoje em diante não temos mais escolha na opacidade das sociedades contemporâneas: somos obrigados a ter confiança. "A motivação e a regulação deste comportamento tornaram-se a tal ponto objetivas que a confiança não exige mais o verdadeiro conhecimento da pessoa." Ela teria se tornado um mecanismo irrefletido ${ }^{18}$.

Abordando a questão da confiança, Simmel exprime as preocupações da modernidade quanto à incerteza; refletindo certa relação com a temporalidade, com o futuro. A confiança à qual nos ligamos aqui é um mecanismo da ordem da escolha, da reflexão ou, ainda, da evidência, do engajamento ${ }^{19}$. Simmel, discernindo as fronteiras limites da confiança, esboça um quadro de funcionamentos, de fenômenos de confiança: (entre) "tudo saber" (quem) não requer a confiança e nada saber que suscita o medo de "ter confiança". Ele verá na confiança uma forma de saber "anterior ou posterior" sobre um ser humano. Simmel acrescenta que "a confiança é também um estado intermediário entre o saber e o não-saber sobre o outro. Aquele que tudo sabe não precisa ter confiança, aquele que nada sabe não pode razoavelmente não ter confiança”"20.

Simmel havia observado na modernidade uma parte de saber e de não saber que "devem se combinar para que se torne possível a deci-

17. Simmel, Sociologie, cap. V, "Le secret et la société secrète", op. cit., p. $356-357$.

18. Ibid., p. 56.

19. 0 que nos interessa aqui não é a confiança quotidiana informal, ligada ou confundida com os automatismos: nós nos dedicamos à confiança refletida, que se torna objetiva e formal nos representantes de um poder, instituições políticas, parlamentares, jurídicas e educativas.

20. Ibid. , p. 356. são individual baseada na confiança”, acrescentando que se tratava de um saber que respeitava uma esfera do íntimo separada de uma esfera exterior, "um saber totalmente geral, que concerne apenas ao aspecto objetivo da pessoa, além do qual ela poderá guardar segredo sobre sua individualidade pessoal" 21 .

0 capítulo que Simmel consagrou na La Philosophie de l'argent à la différenciation de la personne et de la propriété à liberdade individual, depois à objetivação técnica pelo dinheiro é profundamente esclarecedor neste aspecto. Ele mostra realmente que o processo de separação entre as pessoas e as coisas libertou a pessoa das coisas. Ele ainda mostra que se trata de uma separação indissociavelmente psicológica, sociológica e econômica, concomitante com a gênese da individualidade moderna; ela é condição da autonomia da pessoa ou, pelo menos, de uma dimensão da autonomia ligada ao eu íntimo.

Simmel acrescenta que a economia monetária protegia um modo de divisão da pessoa, distinguindo a pessoa de seus bens, contribuindo para uma autonomia - limitada - desta pessoa. 0 que o leva a distinguir uma subordinação subjetiva de uma subordinação técnica.

Esta concepção da pessoa protegida e garantida por esta separação entre bens e pessoas, acompanhando-se de uma separação entre esfera exterior e esfera do íntimo, vai evoluir com as tecnologias contemporâneas: além disso, ela vai ser questionada precisamente nos próprios princípios da avaliação em curso nos mecanismos contemporâneos.

\section{Formas de dependência: subordi-} nação técnica, subordinação subjetiva

A explicação desta subordinação e desta dependência nos parece hoje em dia particularmente interessante: Simmel discerne uma subordinação subjetiva, pessoal e moral dos sentimentos de opressão, que podem ferir, ou

21. Ibid.., p. 356-357. 
até aniquilar a integridade e a dignidade de uma pessoa; ele a distingue de uma subordinação técnica na qual o indivíduo não é submisso enquanto pessoa na relação consigo mesmo, em seu foro interior. Seria, portanto, a autonomia do eu restrito, íntimo, o espaço interior, o sentimento de propriedade de si mesmo que asseguraria e garantiria a integridade supondo o respeito, a confiança no outro, a não intrusão.

Simmel dá como exemplo o trabalhador moderno no qual é "possível discernir "um crescimento da consciência de si": ligado ao fato de que "ele não se sente mais submisso enquanto pessoa"; "fornece somente uma prestação fixa com precisão", e acrescenta: "Esta prestação deixa mais leve a personalidade como tal, na medida em que for... mais impessoal e mais técnica"22.

A leitura de Simmel nos leva assim a colocar que o sentimento de propriedade de si, o sentimento de ser proprietário de si é condição da autonomia da subjetividade. E que o caráter objetivo da subordinação e da submissão não questiona, nestas condições, a confiança em si mesmo.

Simmel dá ainda o exemplo do corpo de oficiais; diz ele que "a subordinação cega ao superior hierárquico não é sentida como uma humilhação, porque ela constitui pura e simples necessidade, tecnicamente incontornável, dos objetivos militares,aos quais todo superior está sujeito, de maneira não menos estrita, mas também não menos objetiva”. Ele conclui então que "a honra e a dignidade da pessoa se situam totalmente além desta superioridade e subordinação"23: esta forma de organização poderia comandar apenas as aparências, o "uniforme", não poderia de forma alguma governar o eu íntimo. Pelo contrário, ela o protege pelos rituais, os códigos e as formas.

Quando as relações de superioridade e subordinação são separadas da subjetividade pessoal do indivíduo, acrescenta ainda Simmel, elas se limitam apenas a ser "pura técnica

22. Simmel, Philosophie de l'argent, op. cit. p. 417.

23. Ibid., p. 419 externa”, o que se produz claramente com os rituais na disciplina; mas isto se torna mais problemático nas sociedades de controle, e mais ainda no controle contínuo, com referência às técnicas de gerenciamento que hoje em dia confundem as duas formas de submissão.

Em seguida, Simmel distingue o salário parcelado do salário horário, que lhe parece "mais digno do homem, porque pressupõe uma confiança maior e confere um pouco mais de liberdade no trabalho". Ele "vê um grau ainda mais elevado desta confiança no emprego": neste, efetivamente, "a prestação particular fornece ainda bem menos o critério direto da remuneração, sendo as prestações pagas globalmente, incluindo todos os riscos de incapacidades humanas" 24 .

Este tipo de trabalho é considerado mais digno porque a confiança que o acompanha afasta a ideia de controle, de medida e de avaliação. Não quantificada e não quantificável, a confiança testemunha a estima que se tem pelo outro. Assim compreendemos em que aspectos os empregos, as funções e, mais além, os cargos constituem meios de exprimir a confiança em um indivíduo e lhe assegurar a autonomia, protegendo-o assim da dependência.

Simmel mostra o caso do "alto funcionário cujo tratamento não tem mais nenhuma relação quantitativa com suas prestações particulares; trata-se de uma "renda" que apenas lhe permite um nível de vida de acordo com sua condição, seu estado e seu cargo". Em seguida dá um exemplo ainda mais evidente, do virtuose cuja remuneração não poderia "contribuir para a manutenção do artista” 25 .

Esta recusa em medir, avaliar, de cifrar esta dissociação entre a prestação econômica e a personalidade, ou ainda o reconhecimento da impossibilidade de avaliar, nos leva a concluir que há uma parte de inavaliável no trabalho, na criatividade e no caráter excepcional de um desempenho.

24. Ibid., p. 423.

25. Ibid., p. 424. 
Esclarecendo os processos que condicionam sua existência, Simmel oferece uma interpretação de conjunto. "A liberação da personalidade" que exige a "diferenciação com a prestação objetiva" constitui seu elemento essencial. Simmel distingue então dois casos: "aquele em que somente o trabalho fornecido é objeto de apreciação e de um preço que considera a objetivação crescente da prestação, que finalmente entra sozinha na circulação econômica, deixando a personalidade de fora"; o outro caso se liga à "manutenção da personalidade global": é o sentido que convém dar ao "pagamento de honorários", implicando que " $a$ prestação particular não tem equivalente econômico direto". "Nos dois casos", sublinha Simmel, "a personalidade é liberada da pressão" que lhe é imposta pela sua dependência monetária explícita "à prestação objetiva particular" 26 .

Somente a prestação deveria ser objeto de apreciação, e a personalidade não deveria em caso algum ser objeto de uma apreciação no sentido estrito, de um "preço".

Dentre os bens inavaliáveis, a fidelidade constitui a seu ver a própria condição da existência durável da sociedade. "Sem o fenômeno que chamamos de fidelidade", escreve ele, "a sociedade, sob a forma em que existe realmente, não teria nenhum meio de subsistir em qualquer duração”. No conjunto dos fatores "que conservam e sustentam" a sociedade, Simmel distingue alguns componentes elementares e outros mais contingentes. Porém todos eles "não poderiam preservá-la da decomposição, se não fossem completados pelo fator fidelidade" 27 .

A fidelidade nasce de um modo de vida estável: ela é o sentimento específico que busca a conservação e a manutenção da relação com o outro. "Se acontece que a relação prossiga e dure, aparece então, interagindo com sua continuidade e persistência, um sentimento particular, ou ainda: a situação psíquica original e fundadora se transforma

26. Ibid., p. 425.

27. Simmel, Soziologie, "Excursus sur la fidélité et la gratitude" op. ct., p. 570. (nem sempre certamente, mas em muitos casos) de maneira a gerar uma forma particular que chamamos fidelidade" 28 .

A propósito de um grande número de relações ou vínculos que unem os homens entre si, é preciso esperar - o que é, de modo geral, uma das condições da existência da sociedade - que o simples hábito de estar juntos e o simples fato de uma relação adquirir certa duração conduzam... à presença do sentimento" ${ }^{29}$. Simmel então revela a possibilidade de estender a fidelidade, de ver nela um fator explicativo da sociedade e do vínculo social, "o fato de estar junto coopta de certa maneira os sentimentos que lhe correspondem de modo específico, uma vez que estes sentimentos não estavam presentes no início e não contam entre as causas que deram origem à relação" ${ }^{30}$.

Certo tipo de sociedade mercantil e de economia monetária protege o inavaliável em cada pessoa, como mostrou Simmel ao distinguir subordinação objetiva e subjetiva, mostrando-se sensível ao papel crucial da confiança.

A economia monetária assegurava um modo de divisão da pessoa, manifestando confiança em um foro interior desconhecido e inavaliável.

De certa forma quase à mesma época que Simmel, é o que havia pressentido Weber observando os funcionamentos da universidade, "o papel crescente do número, a exigência da utilidade para um número ainda maior: ela se desenvolvia contra o valor que se dava à singularidade e à originalidade do indivíduo. Pode-se então compreender, concluía Weber, que "o número dos auditores" tenha se tornado "um critério numérico tangível do valor, enquanto a qualidade do sábio pertence ao domínio do imponderável" 31 .

28. Ibid. p. 572 .

29. Ibid.

30. Ibid.

31. Supiot, L'Esprit de la Philadelphie, op, cit., p.81. 
0 numérico e o afastamento da singularidade do indivíduo vão se desenvolver de forma concomitante. É precisamente este ponto que foi transtornado, segundo a leitura de Supiot, com a "tentativa de metamorfosear toda espécie de qualidade singular em quantidade mensurável" ${ }^{32}$.

\section{Sobre a submissão; lei impessoal, vínculos pessoais}

As sociedades neoliberais contemporâneas têm uma visão mercantil e utilitarista da sociedade conduzindo à ideia de que doravante tudo tem um preço, mesmo os bens sem pre$\mathrm{ço}^{33}$. Estas sociedades, que conhecem uma crise intensificada da relação com a temporalidade, tendem a desconhecer, reduzir e até mesmo contestar o valor, o interesse e, em consequência, a manutenção e a proteção de bens sem preço, tais como a confiança e a fidelidade: estes bens supõem a duração e demandam certa relação com o futuro.

"Em tal mundo, o governo pelas leis cede lugar ao governo pelos números", observa $\mathrm{Su}-$ piot, lembrando que as leis "gerais e abstratas 'supõem' garantir as liberdades de cada um ${ }^{34}$ ". Supiot declara que tal governo "repousa sobre o exercício da faculdade de julgar", isto é, em particular, sobre "operações de qualificação jurídica" e "de interpretação de textos cujo sentido jamais será definitivamente fixado". "Pelo contrário, a 'governança pelos números' repousa sobre a faculdade de cálculo, isto é, sobre as operações de quantificação" e, acrescenta ainda, sobre "a programação dos comportamentos..." 35 .

32. M.Weber, Le Savant et le Politique, Paris, Plon, 1959, p. 60-61.

33. As deferências e as atenções ligadas tradicionalmente à esfera familiar ou social não encontram mais lugar nas sociedades neoliberais, que veem, com o declínio das proteções, a ascensão das condições precárias que se estendem aos trabalhadores pobres, desaguando num confronto entre pobres e ricos, fracos e fortes. Deferências e atenções estão de agora em diante colocadas na mira dos políticos sociais sob a denominação de "care", enquanto a pressão moral na esfera familiar ou profissional surgida nos anos 1990 viu-se em seguida qualificada, institucionalizada, jurisdicionada no início dos anos 2000. Ver M. Sanchez Mazas, G.Koubi (dir.); Le Harcèlement. De la société solidaire à la société solitaire. Bruxelas, Edições da Universidade Livre de Bruxelas, 2005.

34. Supiot, op.cit., p.77. (sublinhado por nós).

35. Ibid., p. 78. (sublinhado por nós)
Já não é tanto o inavaliável em cada pessoa que recuou, não sendo mais protegido pela lei, quanto o estatuto do indivíduo consideravelmente modificado em sua relação com o limite constituído pela lei e, em consequência, na sua relação com o outro. Supiot observa realmente a dimensão ameaçadora que pode constituir a subjetividade de cada um levantada contra o Direito, referindo-se à "pulverização do Direito em direitos subjetivos": a mudança de filosofia que afeta o Direito, a passagem da lei ao contrato o redesenha, abrindo caminho ao "ajustamento mútuo de indivíduos" 36 . Conclui então que o indivíduo é de hoje em diante "reduzido ao estado de mônada contratante e calculante" vivendo "num mundo que se tornou inteiramente calculável e programável", um mundo, acrescenta ainda, "raso e sem mistério" ${ }^{37}$. Não é a única parte de inavaliável em cada pessoa que se apagou, porém de uma maneira ainda mais geral o reconhecimento da própria existência de inavaliável, de inédito, de liberdade, de infınitude. Numa sociedade de controle contínuo, o estatuto do silêncio e do invisivel muda em profundidade: isto pode ser visto na lei que supunha a existência do explícito e do implícito mais ou menos separados por uma fronteira: no contrato, somente o explícito é credível, o implícito, banido, tornou-se uniformemente proibido ${ }^{38}$.

Simmel também discernira a natureza e o grau de imbricação entre os bens objetivos e subjetivos atuantes na propriedade de si, suscetível de conduzir a uma subordinação técnica, objetiva ou subjetiva. Supiot ressalta atualmente algo que nos parece particularmente interessante: “A explosão do Direito em direitos

36. Ibid., p. 48. (sublinhado por nós)

37. Ibid., p. 48 e p. 77. Supiot observa assim com muita justiça que "as categorias de pensamento através das quais identificamos e classificamos os objetos naturais não são...seres matemáticos", op.cit., p. 81.

38. Ver, a respeito do implícito e da questão do silêncio, "L'Art de se taire (1774), reeditado em 1986, (7ª reedição 2007), ed. Jerome Millon, apresentação J.-J.Courtine, Cl.Haroche, assim como Histoire du visage. Exprimer et taire ses émotions XVI - início XIX século (1988), Payot, 3a. Reedição 2007: sobre o estatuto do invisível, ver recentemente $\mathrm{Cl}$. Haroche "L'invisibilité interdite" em Les Tyrannies de la visibilité (N.Aubert, Cl.Haroche. no prelo nas edições Érès). 
subjetivos" inscreve-se no contexto de sociedades individualistas narcísicas ${ }^{39}$, sociedades que, individualizando o indivíduo, o colocam no centro da sociedade e de políticas sociais sem, em contrapartida, lhe oferecer mais liberdade, mais escolha real, mais proteções econômicas e sociais.

A lei, doravante longe de proteger igualmente os indivíduos pelas regras abstratas, em parte imprecisas, destinadas a serem aplicadas em casos diferentes, com a extensão do narcisismo faz atualmente do ser de cada um o princípio da lei, "a lei para cada um" e "cada um para a lei", constituindo, assim, "a expressão jurídica do narcisismo que caracteriza o último estado da cultura no Ocidente" 40 .

Supiot assinala que o narcisismo, paradoxalmente, apagou a singularidade de cada um, isolando o indivíduo e obrigando-o a modos de dependência que não lhe deixam nenhuma escolha, "cada um se vê inserido numa rede de vínculos de dependência (...). Cada indivíduo deve servir o melhor possível aos interesses daqueles de quem depende e deve poder contar com a lealdade daqueles que dependem dele. É a inscrição nos vínculos pessoais, e não a submissão a uma mesma lei impessoal, que define a condição jurídica dos homens, tanto nas suas relações mútuas como nas suas relações com as coisas" 41 .

A personalização dos vínculos, das relações públicas e profissionais e a psicologização do conjunto das relações na sociedade mudaram em profundidade os modos de dependência. 0 intimo, a parte inavaliável em cada um, tende a ver-se reduzido no indivíduo: assim é o caso do trabalhador pós, hiper e super moderno, que se vê confundido com o social. 0 controle contínuo avalia atualmente

39. Sobre o narcisismo, ver Cl. Lasch, La Culture du narcisisme, La vie américaine à un âge de déclins des espérances (1979), ed. Climats, 2000. 40. Supiot, op.cit., p. 101, (grifo nosso). Enquanto a dinâmica do Ocidente se desenvolvia nas sociedades onde os costumes, como coloca Elias, eram civilizados e regulados por códigos de civilidade aprendidos e transmitidos, pareceria que de agora em diante cada indivíduo constituiria sua própria referência nas sociedades individualistas e narcísicas. Ver N. Elias, La Civilisation des moeurs, op.cit. e La Dynamique de l'Occident, op. cit.

41. Supiot, op.cit., p. 104-105. o indivíduo no trabalho sem protegê-lo, reconhecendo nele uma dimensão mínima de iniciativa em uma atividade que lhe parece cada vez mais complexa, ou até mesmo ininteligível: este controle supõe uma divisão do trabalho em que reina uma especialização cada vez maior e por isso um descarte do pensamento geral, ou simplesmente do pensamento.

Ser único. Tornar-se comparável, depois intercambiável

0 contrato não produz somente efeitos sociais, políticos e jurídicos: ele toca no estatuto das pessoas, na sua relação com o tempo o longo tempo do projeto lhes será doravante proibido, de tal forma se encontram entregues ao imediatismo e à urgência da satisfação das necessidades imediatas. Sua independência intelectual, suas capacidades de manifestar a criatividade e a inventividade parecem constantemente entravadas.

A exemplo de Supiot, J. A. Miller e J. C. Milner, observam que o segundo plano da avaliação está ligado, entre outros nas sociedades contemporâneas, a uma mudança referente à filosofia no Direito.0 contrato é muito mais restritivo que a lei no que se refere ao que é proibido: "Na lei, ressaltam eles, o que não é mencionado não é expressamente proibido e o que não é expressamente proibido é permitido". Eles observam que "não estamos mais completamente num regime de lei, estamos num regime onde o contrato emerge; ora, no contrato, o que não é expressamente permitido não é absolutamente permitido" ${ }^{42}$.

É precisamente o que temiam Miller e Milner: tornar o sujeito único comparável, mensurável. Ao contrário “da psicanálise (em que) o método exclui a comparação, nós não comparamos, nos ligamos ao único. Acolhemos cada sujeito... como incomparável". A avaliação procura obter a conformidade do indivíduo a um modelo. A avaliação tem por objeto o es-

42. Miller, Milner, Voulez-vous être évalué? op.cit., p.24. 
tatuto do indivíduo, ela "faz passar um ser de seu estado único ao estado de um entre outros", ele se torna comparável, tem acesso ao estado estatístico, de onde pode rapidamente se tornar intercambiável, o que leva os autores a ver na “comparação, o cerne da avaliação" ${ }^{43}$.

Estes autores destacam que a singularidade do indivíduo, que está no centro da ação psicanalítica, tende doravante a ser evacuada pelas ciências humanas: elas aceitam serem conformes com as ciências exatas. "É o que Gauchet tinha igualmente assinalado recordando que 'a transposição de seus métodos para o domínio das humanidades e das ciências humanas e sociais' foi 'inspirada pela mesma preocupação' que a das ciências exatas, "estimular seu rendimento" ${ }^{44}$.

Gauchet recorda o argumento reiterado desta inspiração: a medida que vai enfim permitir "sair dos trâmites impressionistas do passado". Ele atribui os mecanismos da avaliação às ciências exatas, que assim reduziram as ciências humanas e sociais "a alguns segmentos conformes às suas exigências, entre ciência econômica e ciências cognitivas", julgando que nelas se reconhece "enfim o verdadeiro, o sério, o sólido" ${ }^{45}$ !

Esta transposição "só pode ter por consequência a negação daquilo que faz seu sentido e interesse”. Gauchet conclui que ela "constitui uma catástrofe para as disciplinas humanistas" 46 . A avaliação, "longe de estimular a inventividade e a criação”, desenvolve o conformismo e previne o inavaliável.

Medir o universo interior é ignorar sua especificidade, suprimindo a representação de um espaço e de um ritmo temporal próprio ao universo interior de cada $\mathrm{um}^{47}$. Qual o tipo de personalidade mais conveniente, que

43. Ibid., p. 58, p. 59.

44. Gauchet, op.cit., p. 160 , p. 159.

45. Gauchet, op.cit. p. 158, p.159.

46. Ibid., p. 160 , p. 159 .

47. Considera-se uma necessidade estimular 0 rendimento contra 0 inavaliável, ligado à parte de singularidade irredutível de cada um. Em compensação, este inavaliável, característica dos funcionamentos financeiros mais opacos, é concedido como inelutável. tipo de personalidade se desenvolve de acordo com estas exigências? A subjetividade de tal indivíduo deságua em certa inconsistência do eu que se reflete na falta de continuidade e de engajamento nos vínculos e, mais ainda, apresenta uma inaptidão para certos tipos de vínculos que supõem a duração e a continuidade nos afetos.

A propriedade de si a que se referiu Simmel não se apoiaria mais nas qualidades, aspirações e valores, mas na capacidade de "se desligar", de se livrar do outro como de si mesmo. Trata-se de um tipo de economia psíquica que implica, a longo prazo, a supressão de si: a propriedade de si poderia doravante chegar à inconsistência do eu.

A valorização do desapego na relação consigo mesmo e, em consequência, na relação com o outro, ignorando a história dos vínculos entre indivíduos, induzindo à intercambiabilidade, chega a uma equivalência generalizada incompatível com a confiança que supõe ausência de controle, de domínio e uma forma de abandono. Ora, este desapego leva a uma supressão, ou pelo menos a um declínio da confiança no outro e em si mesmo, podendo desaguar em formas de arrogância ilimitada.

Gauchet, em um ensaio consagrado à psicologia, designada pela personalidade contemporânea como inatingível e incontornável, mostrou o papel decisivo do desapego: o indivíduo contemporâneo apenas troca e se liga no modo da prudência, do controle de si e do domínio, que toma a forma geral do afastamento. No próprio instante em que participa, ele se retira. Ele se afirma quando se desliga ${ }^{48}$.

Milner e Miller fazem uma descrição do tipo de personalidade requerida pela avaliação em diferentes níveis: o indivíduo deve saber se curvar, submeter-se aos códigos em vigor, à linguagem e, ao mesmo tempo, manifestar o medo, o receio da audácia, da criatividade e da liberdade, saber se mostrar e estar

48. Gauchet, "Essai de psychologie contemporaine", Galimmard, Le Débat, n. 99, março/abril 1998. 
de acordo com o que se espera dele. Gauchet chega ao ponto de dizer que é "a desconfiança com relação ao julgamento individual (que)... organiza este sistema... concebido para dissolver a iniciativa, em todos os níveis, na dependência do meio profissional" 49 .

Ele observa e detalha a existência de mecanismos de defesa e de proteção corporativas, burocráticas, o cuidado permanente com a mais extrema especialização desprovida de qualquer interesse que não seja constituir "formas de validação auto-referenciais", assegurando, assim, "a subtração à crítica" e desencorajando o exercício do julgamento crítico, incitando o recurso a "uma linguagem acessível aos únicos dependentes da subdisciplina", constituindo "o meio mais econômico de se construir uma fortaleza inexpugnável" 50 .

Gauchet se atém aos procedimentos de publicação ligados a "um ritual ao mesmo tempo de integração e de submissão às autoridades da tribo", sublinhando que é preciso saber "se situar com relação às posições estabelecidas, em resumo, estamos no campo, como resume uma forma tribal que diz tudo". Ele revela enfim "esta finalidade oculta (que) se encontra na pilotagem da pesquisa" ${ }^{51}$.

Miller e Milner discernem, por sua vez, "uma política da avaliação" que consiste em usurpar "o saber do outro, em obter que ele entregue o saber que tem de sua própria prática" e que descrevem nestes termos: "um tem alguma coisa para dividir, que é o saber que tem de sua prática, enquanto o outro nada tem, nenhum saber efetivo, a não ser seu método, a forma - em oposição à matéria apresentada pelo outro - e ele tem também o poder de acreditar ou não, de reconhecer ou não o puro poder do tampão" 52 .

Lindsay Waters, por sua vez, vai pesquisar esta avaliação nos meios universitários.

49. Gauchet, Vers une société de l'ignorance?", art.cit., p. 163.

50. Ibid., p.162.

51. Ibid.

52. Miller e Milner, op. cit., p. 60.
"Saber tudo sobre quase nada"53:

a estigmatização do pensamento geral

Sobre as origens e os efeitos destes saberes especializados e expertos é que trabalhou Lindsay Waters. Ele observa uma crise geral no exercício do ajuizamento imputado à pressão exercida pelo mercado sobre o trabalhador do pensamento: encorajando ou privilegiando o automático e o repetitivo, o mercado desenvolve um saber instável, efêmero e não cumulati$\mathrm{vo}^{54}$. Waters observa que "o universitário típico sente cada vez mais intensamente pelo fato de que trabalha para produzir". "Os empresários arrancaram todo o poder dos cientistas e desenvolveram uma cultura da avaliação que visa um controle administrativo crescente da vida institucional e profissional" 55 , sublinhando com justiça que a sociedade está "doente da gestão" ${ }^{56}$.

Waters percebe "um vínculo de causa e efeito entre a exigência corporativista de produtividade e o fato de que toda publicação é reduzida à ideia de número". Ele vê sua origem em uma argumentação aparentemente ilimitada sobre o controle administrativo, observa que o mercado gera formas de pressão que aumentam a produtividade e constata que "os problemas de avaliação invadiram hoje em dia as instituições americanas" ${ }^{27}$.

Waters debruça-se sobre a natureza do saber universitário, que "supõe a leitura, a apropriação e a transmissão", e aí parece hesitar, depois explica esta hesitação, sublinhando o papel decisivo do tempo, da duração, do prazo e da pausa para poder pensar dentro do conhecimento, ao contrário da instantaneidade da informação. "Um universitário pode levar dezenas de anos antes de ler a tese em latim da universidade

53. A expressão é de Gauchet: "Vers une société de l'ignorance?", art. cit. p.162.

54. Retomamos aqui num contexto mais geral uma passagem de uma análise do texto de Waters, op.cit., consagrada à "Crise da consciência contemporânea e expansão de um saber não cumulativo" (cf. Haroche), publicada em Cahiers internationaux de Sociologie, vol. CXXV, julho-dezembro 2008, citado p. 342.

55. Waters, op. cit. p. 20.

56. A expressão remete à obra de Vincent de Gaulejac, La Société malade de gestion, Paris, Seuil, 2005.

57. Waters, op.cit., p. 6-7. 
de Berlim escrita por certo James Henry Breast permitindo a descoberta do mundo esquecido de Akhénaton." Waters insiste com propriedade no fato de que "o papel do saber é apreciado em termos de profundidade e duração, não em termos de extensão e superfície" ${ }^{\text {58. }}$.

Sendo o espírito empresarial movido atualmente por um movimento incessante e uma atividade desenfreada submetida à urgência e desprovida de reflexão, uma produtividade cega e desengajada tenderia doravante a ser despojada de ideias, representação e imaginação. Waters contempla então o papel da técnica - mais ainda da produtividade - nas sociedades contemporâneas, observando que agora "o que conta é o produto". Ele constata que "o aumento das exigências em matéria de produtividade é acompanhado de uma interdição aparente em matéria de inovação intelectual", o que é explicado pelo sistema neoliberal, que visa suprimir tudo o que não é imediatamente útil ou rentável aos olhos da sociedade ${ }^{59}$.

Waters constata que "a ideia dominante" na universidade de hoje é evitar as ideias, "incitando a meditação sobre as relações entre contar, medir, avaliar e quantificar por um lado" - o que não é naturalmente idêntico a apreciar, julgar e discernir - "e ler, pensar e refletir por outro lado" ${ }^{\circ}$.

Waters conclui suas ideias sublinhando que o pensamento exige liberdade, que a exigência de produtividade lhe é contrária na medida em que questiona a própria possibilidade de pensar. Ele discerne no termo "autoridade" dois elementos que diferem em profundidade: o entusiasmo, o pensamento, a posição, o engajamento do autor e a parte de autoritarismo - congelado, parado - devido ao componente mecânico, irreversivel e consumado do impresso, daquilo que é publicado. Diz ele: "Há no pensamento uma parte de liberdade de pensar e de palavra que resiste à execução material (...). Há um conflito percebido sempre pelas pessoas profundamente

58. Ibid., p. 19

59. Ibid. p. 36, p. 53.

60. Ibid. , p. 70. inteligentes entre o autoritarismo do escrito e a autoridade que se procura tomando a palavra e a publicando"61.

0 desenvolvimento das tecnologias e a massa crescente de informações contínuas nas sociedades contemporâneas contribuem para formas inéditas de fragmentação que provocam um abalo na relação consigo mesmo, conduzindo a uma incerteza, às vezes radical, quanto a si mesmo e ao outro, abrindo assim caminho para uma profunda incerteza psíquica.

\section{Instaurar um sistema paralelo:}

medir outra coisa

As abordagens de Supiot, Miller e Milner, Waters, Gauchet e Zarka são às vezes muito próximas: elas se cruzam, se recobrem e de certa maneira dialogam constantemente.

Seguindo as análises de Waters em certas questões, Zarka as precisa em um estudo consagrado ao saber, pesquisando, por sua vez, a questão da avaliação. Ressalta que a avaliação sempre foi feita, mas o que se entende agora por avaliação não tem nada a ver com o que se fazia no passado. "Admitia-se que não se deviam definir critérios demasiadamente estritos porque estes poderiam mascarar, por exemplo, o caráter inesperado, paradoxal e particularmente inventivo de um resultado"62. Se ele reconhece a existência de erros de apreciação e injustiças, reconhece também que o recurso a um novo exame poderia permitir a reparação destes erros. 0 sistema da avaliação, apresentado de hoje em diante como um conjunto de medidas "objetivas, factuais, cifradas", tornou-se peremptório e definitivo: "Todo reexame torna-se por assim dizer impossível" ${ }^{63}$.

Zarka lembra que "a avaliação é sempre subjetiva e relativa”, mas que esta "subjetividade... deve permanecer invisível” e que, por este motivo, "procura esconder-se atrás de

61. Ibid., p. 83 , p. 85.

62. Zarka, art. cit., p. 115.

63. Id., p. 3 e p.119-120, p. 115. 
uma matemática"64. Insiste ainda sobre o fato de que a "avaliação (...) mede outra coisa" 65 . E pensamos que esta outra coisa corresponde, entre outras, à parte inavaliável que protege a interioridade do indivíduo: a avaliação quer realmente reduzi-la, se não descartá-la “(levando) a inquisição até a interioridade" 66 , a fim de governar e dominar tanto os indivíduos como os comportamentos, as atividades e as reflexões, tendo como objetivo a produtividade, tornando-os assim úteis à sociedade.

A avaliação recusa e persegue o inavaliável, o qual supõe certa confiança, requer uma margem de liberdade e de iniciativa, que pode dissimular a insubmissão, a capacidade de resistência, de recusa ou, até mesmo, de revolta. A avaliação conduz à supressão do exame e do julgamento crítico em nome da "eficácia, da adaptação e da inovação", com a ideia de lutar, até mesmo de erradicar o resíduo, a perda, o desperdício e o descrédito: tudo serve, "tudo deve servir", tudo deve ser reciclado. Zarka vê então na adaptabilidade "a palavra-chave da avaliação”, que supõe a supressão do inavaliável, da dúvida, da circunspecção, da hesitação, de sucessivas opiniões não definitivas e, naturalmente, da recusa. A obrigação de mudança, movimento e ritmo se opõe ao respeito pelo ritmo pessoal, pelo ofício, pela habilidade, pela prática do artesão, tendendo a entravar o sentimento de continuidade, o sentimento de si mesmo e, finalmente, a desqualificar e até mesmo tornar impossível o exercício do pensamento.

Que tipo de personalidade, de espírito e de consciência, que forma de sensibilidade esta educação encoraja? Uma personalidade flexível, adaptável, conforme e suscetivel de "adaptar-se a objetivos fixados anteriormente". 0 indivíduo não cessa atualmente de escrutinar, avaliar, excluir e estigmatizar, porém não se engaja, temendo o outro que não cessa de

64. Id.p.118, p.119. É o que hoje designamos constantemente de cultura da cifra e do resultado. Sobre a linguagem da transparência, ver os escritos de G. Orwell e os de H. Arendt sobre As origens do totalitarismo, em particular o sistema totalitário.

65. Id., p. 115, p. 5.

66. Id., p. 5 . observá-lo: seria necessário que ele se esquecesse de avaliar ou de que é avaliado para continuar a pensar.

Zarka insiste então na dificuldade de resistir a este sistema: sublinha, na verdade, que "a resistência supõe o isolamento, ou até mesmo, a desqualificação pública" ${ }^{67}$. A resistência institucional o é certamente, ela talvez tenha se tornado quase impossivel. Gostaríamos, no entanto, de observar que a resistência intelectual nada tem de impossível: ela supõe a liberdade, a criatividade, a inventividade e a audácia exigidas pela atividade e experiência de pensar, ela implica além do mais a paciência face à falta de eco e à indiferença pelo trabalho de reflexão; ela requer enfim a força de caráter, a determinação, a autoconfiança nos momentos de ausência de reconhecimento.

Gauchet oferece uma conclusão incisiva, tentando perceber uma lógica interna e externa na avaliação, pelo viés do narcisismo nas sociedades de mercado ultraliberal, o narcisismo grupal, "o gosto exclusivo por aquilo que nos assemelha" e, ao mesmo tempo, "a autoproteção" como "o desejo de proteger-se da concorrência em um universo (...) ultracompetitivo" ${ }^{68}$.

As técnicas, os processos, a cultura e a política da avaliação responderiam, como sublinham tanto Milner como Waters, Gauchet, Supiot e Zarka, às exigências da produtividade do mercado, "sob aparências aparentemente incontestáveis. Suas novas modalidades, supondo torná-la mais 'objetiva', fazem dela uma arma de destruição maciça no domínio das humanidades" ${ }^{69}$.

\section{Provar que não somos um espí- rito independente: conhecimento,} conivência

É o que Waters havia pressentido há alguns anos, sublinhando que "as humanidades davam iniciativa e liberdade demais ao

67. Zarka, op. cit., p. 122

68. Gauchet, Vers une société de l'ignorance? p. 155. Ver igualmente J.C. Michéa, L'Apprentissage de l'ignorance, Castelnau-le-Lez, Climats, 1999, assim como os trabalhos pioneiros de C. Lasch sobre o narcisismo.

69. Id., p. 158. 
indivíduo"70. As injunções à produtividade suprimiram agora em diante o tempo de pensar e o juízo crítico: elas contribuíram para excluir o inavaliável, o inclassificável, pelo viés de um saber acreditado. A conivência, então encorajada e favorecida, não poderia ser a confiança vivida por um indivíduo livre.

Waters completa Gauchet e Zarka oferecendo, a respeito do sistema americano, observações que valem, evidentemente, para todos os outros sistemas - notando que "cada vez menos as escolas tolerarão esta espécie de independência com relação às normas de publicações sempre mais rígidas. É como se as escolas dissessem implicitamente que para possuirmos a 'concessão' deveríamos provar que não somos um espírito independente $\mathrm{e}$ nos submetermos às regras e aos objetivos de uma produtividade intensa"71.

A desconfiança tenderia a desenvolver a prudência, o medo, a submissão e a docilidade. Lindsay Waters realça que "uma negatividade profunda invadiu as humanidades deixando liberdade demais ao indivíduo" e que "nos estudos literários uma grande parte deste negativismo consistiu em atacar a teoria" na medida em que ela deixa da liberdade um conhecimento geral e acrescenta que "sua posição antiteórica constitui sua característica essencial”. Waters acrescenta, evocando certos autores, que sua corrente não é tanto "oposta à teoria quanto à consequencialidade (...) a ideia de que qualquer coisa possa fazer uma diferença em nossas vidas"72.

Trata-se, com esta política e cultura da avaliação, dos efeitos do nivelamento, do igualitarismo se exercendo sobre a atividade do pensamento? $\mathrm{Ou}$ ainda de niilismo, de destrutibilidade, de uma hostilidade profunda contra o conhecimento, a razão, a própria idéia de encontrar um sentido para o conhecimento?

70. Waters, op. cit., p.53

71. Waters, op. cit., p. 82.

72. Waters, op. cit., p. $68,69,70$.
Desencorajados, desenganados, amargos - teríamos perdido ou pelo menos renunciado à possibilidade, à própria ideia de inavaliável, de liberdade, de sonho, de imaginação, de capacidade de idealização?

Na metade dos anos 1980, na obra que consagrou a Foucault, Delleuze dizia que a relação consigo mesmo - como espaço de liberdade individual - não estava protegida pelos sistemas institucionais e sociais: ele observava na realidade que "o poder (tinha) cada vez mais invadido nossa vida cotidiana, nossa interioridade e nossa individualidade, que havia se tornado individualizante". Ele pensava no entanto que haveria "sempre uma relação consigo mesmo (capaz) de resistir aos códigos e aos poderes" ${ }^{\text {”3. }}$.

Deleuze concebia a relação consigo mesmo como um “devir permanente”, não cessando "de se realizar, mas se metamorfoseando e mudando de modo. (...) Recuperada pelas relações de poder e saber, a relação consigo mesmo continua renascendo, em outros lugares e de outras maneiras"74.

As modalidades da relação do indivíduo com o Estado, no que se refere à ordem e à proteção, vacilaram em profundidade e foram de certa maneira apagadas. Os modos de formação, de estruturação e de funcionamento da relação consigo mesmo foram abalados pela aparição das tecnologias.

Desde que Deleuze escreveu este texto, as tecnologias se multiplicaram; ilimitadas, elas penetraram, abalaram, metamorfosearam, esgotaram, esvaziaram e minaram a relação consigo mesmo. Hoje em dia é tão evidente que esta relação possa existir, sejam quais forem os tipos e as modalidades destes poderes? É possível proteger esta relação consigo mesmo? Deleuze entendia por sujeito um modo de resistência. 0 que é que se deve entender por modo de resistência, o que ele supõe? A energia, o entusiasmo, o dinamismo, a criatividade, uma ligação com o futuro, com o vir a ser. As sociedades

73. G. Deleuze, Foucault, Paris, Éditions de Minuit (1986/2003), 2006, p. 112, p. 111.

74. Ibid., p. 111. 
de controle ou de comunicação não suscitarão formas inéditas de resistência? Pela flexibilidade e a adaptação do sujeito através da relação consigo mesmo? Mas até onde? Deleuze considera, não superestimaria as capacidades de resistência e a continuidade do sujeito, concebendo ou imaginando outros modos de subjetivação?

Há ou haveria condições em que o sujeito não consegue se realizar, se estruturar, se formar, na medida em que não consegue mais resistir? Esta capacidade de resistência é ainda possível com os mecanismos invasivos e acelerados que anulam nas condições contemporâneas até os limites corporais? Esta resistência está esgotada, minada, diminuída física e psiquicamente pela desmaterialização, por uma adaptação contínua, sem limite, infınita? ${ }^{75}$

\section{Pensar: não ser obrigado a produzir de} forma contínua

Deleuze insistia no fato de que a relação consigo mesmo não cessa de se realizar: a concepção do sujeito, da relação consigo mesmo depende de um conjunto movente onde se percebe o movimento, o entusiasmo, a energia, o dinamismo, o prazer e o desejo. Neste espaço da relação consigo mesmo - quer se trate da consciência, do íntimo, do formulado ou do não formulado ou do simbolismo - persiste, escapando de todo sistema - o inavaliável, o único, a singularidade.

Deleuze lembra que "criar sempre foi diferente de comunicar": convém acrescentar hoje em dia, diferente de produzir. Seriam necessários então momentos de pausa, de não funcionamento, de silêncio, "criar vacúolos de não comunicação, interruptores, para escapar ao controle"76.

75. Sobre estas questões, ver Supiot, que se refere à expressão de Bruno Romano falando de "fundamentalismo funcional" que designa "a nova língua em uso nas instituições comunitárias: não se fala mais de seres humanos, de capacidades profissionais ou de liberdades, mas de capital humano, empregabilidade ou flexibilidade. Estes deslocamentos terminológicos captam as pessoas como coisas e substituem às categorias jurídicas as maneiras de pensamento importadas da física ou da biologia" (op. cit., 141-142).

76. Deleuze, "Controle et Devenir", op. cit., p. 238.
0 trabalho do pensamento é acompanhado de tempos mortos, de momentos inúteis, de momentos de flutuações, de pausas, de diversões, de digressões, momentos que alimentam um trabalho invisivel que se desenvolve na duração e que supõe uma parte inavaliável ${ }^{77}$.

Este inavaliável corresponde a um direito fundamental: $o$ direito de não falar, de se calar, o direito de não ter que produzir e se produzir de maneira contínua, seja qual for o sentido da palavra produzir ou se produzir para poder pensar, fazer, se ativar, criar, mostrando-se atento ao que as humanidades nos transmitem: a medida no sentido em que se é medido, ou se fica medido.

“A avaliação contínua" tende $a$ despojar o individuo da liberdade interior, da experiência interior, do pensamento, "o trabalho do pensamento consiste realmente em conferir ao cálculo um significado, relacionando sempre as quantidades medidas a um sentido de medida”. Um sentido medido ou um sentido repousando sobre a cifra. Porém, "confundir medida e avaliação nos condena a perder o sentido da medida. Porque avaliar não é somente medir, mas referir a medida a um julgamento de valor que lhe confere um sentido"78. A avaliação precisa da medida, mas parece que ela sobretudo encorajou e duplicou a comparação, a comparação permanente com outro ou outros, o que ressalta com justiça J. A. Miller relendo a correspondência de Spinoza com Blyenbeergh: "Esta se refere precisamente ao estatuto da comparação que para ele é justamente uma operação que procede do imaginário. Ele negava que qualquer coisa pudesse faltar a um homem cego. A visão só lhe falta em comparação com outro homem, mas, em si mesmo, nada lhe falta, não mais que uma pedra não é privada de visão. $E$ a comparação que introduz a falta, que não é nada por si mesma"79.

77. Sobre as digressões nos processos de pensamento e memória, ver Freud, "Um trouble de mémoire sur l'Acropole", em Résultats, Idées, Problèmes, II (1921-1938), PUF, 1085, p. 221-230.

78. Supiot, op. cit. p. 81 e 82 (grifo nosso)

79. Miller, op. cit. , p. 65. 
A comparação ou pelo menos a exigência de comparação que, por si mesma garantiria a qualidade científica de um trabalho, de uma ideia ou de um projeto, parece reduzir o científico ao conhecido e à comparabilidade: pode-se então compreender que esta forma de comparação é que está no coração da avaliação. Ela está sem dúvida nas origens longínquas do intercambiável e, mais recentemente, das formas intensificadas de concorrência. Inspirada pelo medo do risco nas sociedades ultraliberais governadas pelas exigências do lucro financeiro, ela só pode ignorar o inavaliável. Da mesma forma que existe um controle contínuo, não podemos ignorar que persiste uma inventividade contínua. É o que um antropólogo como Georges Balandier não cessou de lembrar ${ }^{80}$.

A própria ideia de incomparável, de inclassificável, de inavaliável, a tomada de consciência da existência do inavaliável, sua perpetuação, sua proteção, são doravante cruciais. 0 inavaliável permite a liberdade de pensar, de imaginar e de inventar: em outros termos, permite o imprevisto, o inédito. Permite resistir à estreiteza de espírito, ao espírito sectário, ao espírito tribal no exercício e na experiência de pensamento ${ }^{81}$.

80. Le Dépaysement contemporain. L'immédiat et l'essentiel, op.cit. 81. Ver G.Guglielmi \& Cl. Haroche (dirs.), Esprit de corps, espace public et démocratie, Paris, PUF, 2007.

Claudine Haroche é professora, pesquisadora do Centre National de la Recherche Cientifique (CNRS/Paris) e membro do Núcleo História e Linguagens Políticas. 